\title{
BADANIE OBSZARÓW FUNKCJONALNYCH W WOJEWÓDZTWIE OPOLSKIM - OGRANICZENIA I WYZWANIA ANALIZY DANYCH DLA NIEADMINISTRACYJNYCH PODZIAŁÓW REGIONU
}

\begin{abstract}
Celem artykułu jest przestawienie obszarów funkcjonalnych jako obiektów badań ilościowych. Ich powstanie było odpowiedzią na zapotrzebowania społeczności lokalnych na wspólne rozwiązywanie problemów. Obszar funkcjonalny to obszar szczególnego zjawiska z zakresu gospodarki przestrzennej lub występowania konfliktów przestrzennych, stanowiący zwarty układ przestrzenny składający się z funkcjonalnie powiązanych terenów, charakteryzujących się wspólnymi uwarunkowaniami i przewidywanymi jednolitymi celami rozwoju. Analiza dokumentów strategicznych wskazała kategorie badawcze ważne z punktu widzenia rozwoju tych obszarów. Wyszczególnione determinanty to: rynek pracy i edukacja, ochrona zdrowia i pomoc społeczna, kultura, turystyka i sport, infrastruktura komunalna i mieszkania, stan i ochrona środowiska. Przy pomocy zmiennej syntetycznej skonstruowano dla tych terenów wskaźnik atrakcyjności osiedleńczej. Najwyższy wskaźnik atrakcyjności osiedleńczej uzyskała Aglomeracja Opolska, która dominowała pod względem rynku pracy i edukacji, ochrony zdrowia i pomocy społecznej, kultury, turystyki i transportu, a także infrastruktury komunalnej i mieszkań. Artykuł jest próbą wskazania ograniczeń i wyzwań analizy danych dla nieadministracyjnych podziałów regionu. Badania przeprowadzono w dwóch okresach: w 2010 (kiedy obszarów jeszcze nie było) i w 2016 roku dla najnowszych dostępnych danych. Analizy wykonano przy pomocy programu kalkulacyjnego EXCEL używając jednej z metod wielowymiarowej analizy porównawczej. Problematyka analizy danych dla nieadministracyjnych podziałów regionu jest ważna z punktu widzenia badania istotnych czynników rozwoju regionalnego i lokalnego.
\end{abstract}

Słowa kluczowe: strategia rozwoju, atrakcyjność osiedleńcza, zmienna syntetyczna, obszar funkcjonalny, kumulacja danych na poziomie NTS 5.

\section{WPROWADZENIE}

\subsection{Obszary funkcjonalne}

Zgodnie z definicją przez obszar funkcjonalny należy rozumieć obszar szczególnego zjawiska z zakresu gospodarki przestrzennej lub występowania konfliktów przestrzennych,

\footnotetext{
${ }^{1}$ Dr inż. Katarzyna Widera, Politechnika Opolska, Wydział Ekonomii i Zarządzania, Katedra Ekonomii, Finansów i Badań Regionalnych, 45-036 Opole, ul. Luboszycka 7; e-mail: k.widera@po. opole.pl

Katarzyna Widera,PhD, Eng., Opole University of Technology, Faculty of Economics and Management, Department of Economics, Finance and Regional Research, 45-036 Opole, ul. Luboszycka 7; e-mail: k.widera@po.opole.pl
} 
stanowiący zwarty układ przestrzenny składający się z funkcjonalnie powiązanych terenów, charakteryzujących się wspólnymi uwarunkowaniami i przewidywanymi jednolitymi celami rozwoju ${ }^{2}$.

Obszary funkcjonalne określa się z zapewnieniem:

1. ciągłości i zwartości wyznaczanego obszaru - polegającej na wyznaczeniu obszaru zamkniętego wspólną granicą;

2. dostępności danych wskaźnikowych, umożliwiających wyznaczenie łącznego obszaru, którego zasięg przestrzenny umożliwia rozwiązanie istniejących lub przewidywanych problemów oraz rozwój nowych funkcji tych obszarów ${ }^{3}$.

\subsection{Obszary funkcjonalne w województwie opolskim}

W Strategii Rozwoju Województwa Opolskiego do roku 2020 wskazano, że polityka rozwoju realizowana przez województwo opolskie do tego okresu, bazująca ma ustaleniach krajowych i unijnych dokumentów strategicznych, będzie wykorzystywać terytorialne podejście do zagadnień rozwojowych ${ }^{4}$. Utworzenie obszarów funkcjonalnych w województwie opolskim było zatem naturalną konsekwencję działań władz lokalnych w tym obszarze. Powstałe obszary funkcjonalne mają wspólne cele rozwojowe lub/i wspólne problemy do rozwiązania.

Na terenie województwa opolskiego powstało pięć obszarów funkcjonalnych:

I. Aglomeracja Opolska

II. Partnerstwo Nyskie 2020

III. Subregion Brzeski

IV. Subregion Kędzierzyńsko-Strzelecki

V. Kluczbork - Namysłów - Olesno

Przeanalizowano następujące dokumenty strategiczne:

I. Strategię Rozwoju Aglomeracji Opolskiej na lata 2014-2020.

II. Strategię Rozwoju Obszaru Funkcjonalnego Partnerstwo Nyskie 2020.

III. Strategię Rozwoju Współpracy Subregionu Brzeskiego na lata 2014-2020 z perspektywą do roku 2025.

IV. Strategię Rozwoju Subregionu Kędzierzyńsko-Kozielskiego do roku 2020.

V. Strategię Rozwoju Obszaru Funkcjonalnego Kluczbork - Namysłów - Olesno.

Rys. 1 ukazuje rozmieszczenie obszarów funkcjonalnych w województwie opolskim. Zauważyć należy, iż ok. 97\% województwa opolskiego pokrywają tereny wchodzące w skład pięciu obszarów funkcjonalnych oraz odnotować, iż Subregion Brzeski współtworzy gmina Oława z województwa dolnośląskiego.

Analiza dokumentów strategicznych ukazała kategorie (zbiory czynników) determinujące rozwój tych obszarów. Są to: atrakcyjność inwestycyjna, atrakcyjność turystyczna, atrakcyjność osiedleńcza i bezpieczeństwo. Ze względu na zróżnicowanie i uwarunkowania

\footnotetext{
${ }^{2}$ Ustawa z dnia 27 marca 2003 r. o planowaniu i zagospodarowaniu przestrzennym (Dz.U. z 2017 r., poz. 1073, 1566), art. 2 , pkt 6 a.

${ }^{3}$ Ibidem, art. 49 c, pkt 1.

${ }^{4}$ Strategia Rozwoju Województwa Opolskiego do roku 2020, Urząd Marszałkowski Województwa Opolskiego, Departament Polityki Regionalnej i Przestrzennej, Opole 2012, s. 70.
} 
np. geograficzne, każdy z tych obszarów w różny sposób dokonałby gradacji ważności tych kategorii dla swojego rozwoju.

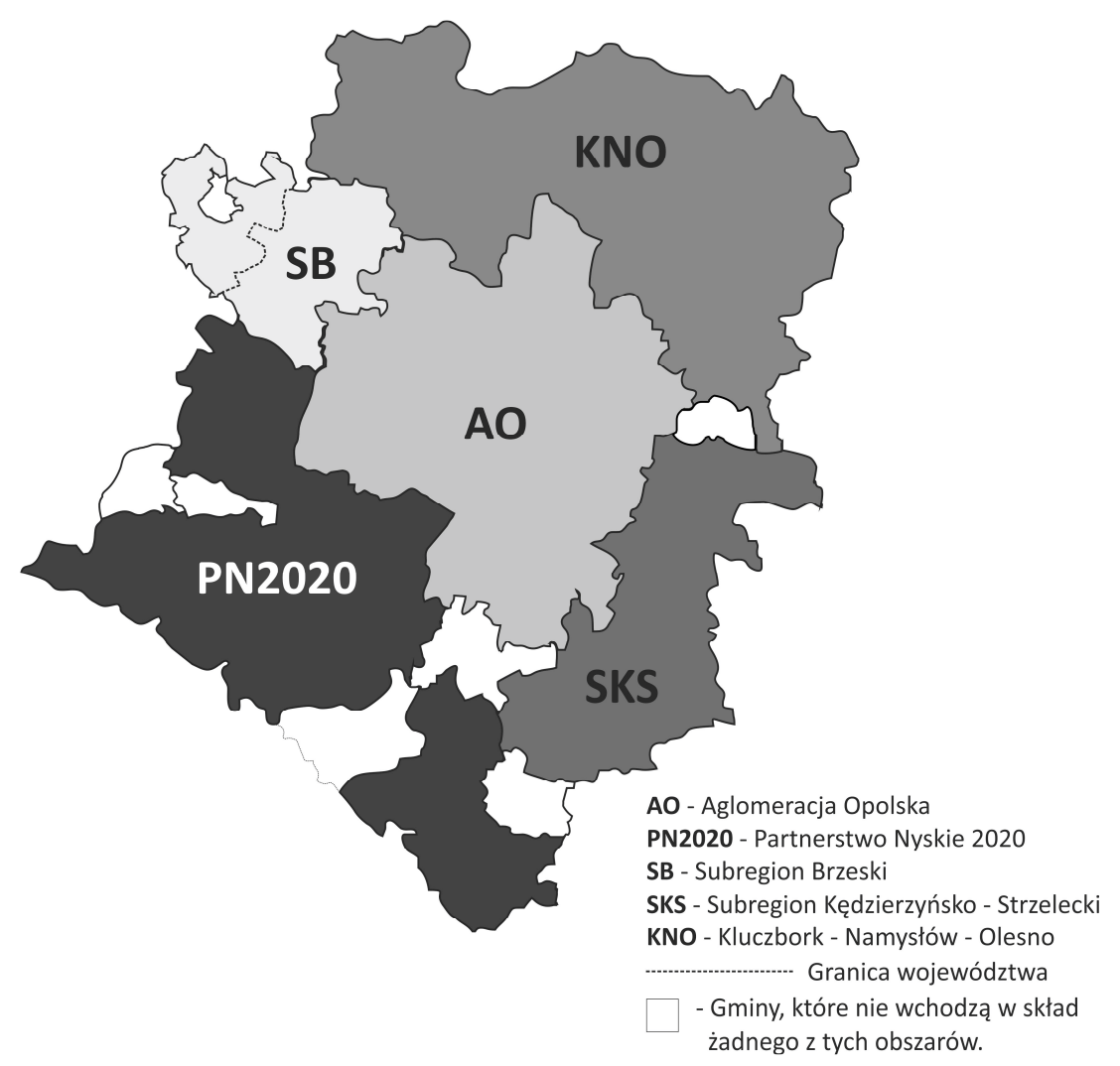

Rys. 1. Obszary funkcjonalne w województwie opolskim

Źródło: opracowanie własne na podstawie danych www.stat.gov.pl

\subsection{Analiza atrakcyjności osiedleńczej obszarów funkcjonalnych}

Po analizie treści dokumentów strategicznych dokonano przeglądu dostępnych danych zastanych. Obiektami badań było pięć obszarów funkcjonalnych, zaś zbiory czynników cechy diagnostyczne - pomocne w opisie wymienionych powyżej kategorii to cechy powstałe z kumulacji cech dotyczących gmin wchodzących w skład poszczególnych obszarów. Dostępne na poziomie NTS 5 dane statystyczne cechuje duża ograniczoność. Stąd jedyną kategorią, którą poddano analizie była kategoria atrakcyjność osiedleńcza. Tabela 1 prezentuje cechy diagnostyczne wybrane do opisu tej kategorii. 
Tabela 1. Wybrane wskaźniki atrakcyjności osiedleńczej wg działów tematycznych

\begin{tabular}{|c|c|c|c|}
\hline & $\begin{array}{l}\text { DETERMI- } \\
\text { NANTA }\end{array}$ & Wybrane wskaźniki ${ }^{5}$ & \\
\hline & \multirow{5}{*}{ 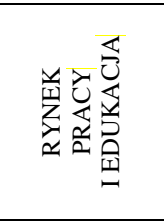 } & 1. bezrobotnych / l. osób w wieku produkcyjnym & $\mathrm{D}$ \\
\hline & & 1. pracujących / 1. osób w wieku produkcyjnym & $\mathrm{S}$ \\
\hline 1 & & dzieci w przedszkolach / na 100 miejsc w przedszkolach & $\mathrm{D}$ \\
\hline & & absolwenci szkół ponadgimnazjalnych / na 1 tys. ludności w wieku 18-20 & $\mathrm{S}$ \\
\hline & & współczynnik skolaryzacji netto w szkołach podstawowych 7-12 & $\mathrm{S}$ \\
\hline \multirow{5}{*}{2} & \multirow{5}{*}{ 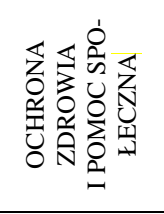 } & 1. przychodni / 10 tys. ludności & $\mathrm{S}$ \\
\hline & & 1. ludności / 1 aptekę & $\mathrm{D}$ \\
\hline & & 1. porad ogółem / 1. mieszkańców & $\mathrm{S}$ \\
\hline & & miejsca w placówkach pomocy społecznej / 10 tys. ludności & $\mathrm{S}$ \\
\hline & & dzieci w żłobkach /na 100 miejsc w żłobkach & $\mathrm{D}$ \\
\hline \multirow{9}{*}{3} & \multirow{9}{*}{ 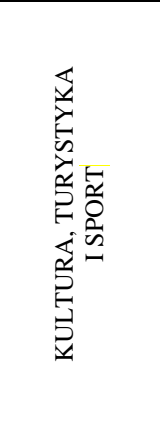 } & czytelnicy / 1 tys. ludności & $\mathrm{S}$ \\
\hline & & wypożyczenia / 1 czytelnika & $\mathrm{S}$ \\
\hline & & widzowie w kinach / 1 tys. ludności & $\mathrm{S}$ \\
\hline & & biblioteki publiczne/ 10 tys. ludności & $\mathrm{S}$ \\
\hline & & miejsca noclegowe / 1 tys. ludności & $\mathrm{S}$ \\
\hline & & korzystający z obiektów noclegowych / 1 tys. ludności & $\mathrm{S}$ \\
\hline & & kluby sportowe / 10 tys. mieszkańców & $\mathrm{S}$ \\
\hline & & ćwiczący / 10 tys. mieszkańców & $\mathrm{S}$ \\
\hline & & $\begin{array}{c}\text { centra kultury, domy i ośrodki kultury, kluby, } \\
\text { świetlice gminne /10 tys. ludności }\end{array}$ & $\mathrm{S}$ \\
\hline \multirow{6}{*}{4} & \multirow{6}{*}{ 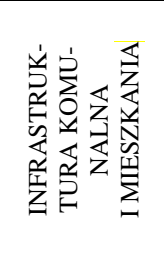 } & powierzchnia mieszkań / 1. ludności & $\mathrm{S}$ \\
\hline & & mieszkania oddane do użytkowania / 10 tys. mieszkańców & $\mathrm{S}$ \\
\hline & & korzystający z sieci wodociągowej w \% ludności ogółem & $\mathrm{S}$ \\
\hline & & korzystający z sieci kanalizacyjnej w \% ludności ogółem & $\mathrm{S}$ \\
\hline & & sieć wodociągowa / $100 \mathrm{~km}^{2}$ & $\mathrm{~S}$ \\
\hline & & sieć kanalizacyjna / $100 \mathrm{~km}^{2}$ & $\mathrm{~S}$ \\
\hline \multirow{3}{*}{5} & \multirow{3}{*}{ 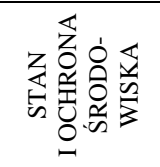 } & zmieszane odpady komunalne zebrane w ciągu roku/ 1 mieszkańca & $\mathrm{D}$ \\
\hline & & $\begin{array}{l}\text { ludność korzystająca z oczyszczalni ścieków komunalnych } \\
\text { w \% ludności ogółem }\end{array}$ & $\mathrm{S}$ \\
\hline & & powierzchnia lasów w \% powierzchni ogółem & $\mathrm{S}$ \\
\hline
\end{tabular}

S - stymulanta, D - destymulanta

Źródło: opracowane przez WUS w Opolu, na podstawie danych z BDL

\section{METODA BADANIA}

Wielowymiarowa analiza porównawcza zajmuje się metodami i technikami porównywania obiektów wielocechowych. Stanowi ona spójny formalnie zespół metod statystycznych służących celowemu doborowi informacji o elementach pewnej zbiorowości i wykry-

\footnotetext{
${ }^{5}$ Wszystkie cechy diagnostyczne wzięte do badania miały charakter wskaźników.
} 
waniu prawidłowości we wzajemnych relacjach tych elementów. Jej zadaniem jest uporządkowanie względnie jednorodnego zbioru obiektów lub cech, w celu podejmowania decyzji wyboru obiektu lub cechy według z góry ustalonego kryterium6 ${ }^{6}$.

W procesie normowania wartości cech statystycznych (wskaźników) diagnostycznych dokonano ich przekształcenia według wybranej metody normalizacji zmiennych. Posłużono się metodą normującą cechy ilościowe tzw. unitaryzacją zerowaną ${ }^{7}$.

W celu doprowadzenia do porównywalności, wskaźniki określające atrakcyjność osiedleńczą badanych obszarów funkcjonalnych, poddano unitaryzacji wg wzorów ${ }^{8}$ :

$$
\begin{aligned}
x_{i}^{\prime} & =\frac{x_{i}-x_{\min }}{x_{\max }-x_{\min }} \text { dla stymulant, } \\
x_{i}^{\prime} & =\frac{x_{\max }-x_{i}}{x_{\max }-x_{\min }} \text { dla destymulant. }
\end{aligned}
$$

Utworzono zmienną syntetyczną jako bezwzorcową miarę określającą poziom atrakcyjności osiedleńczej badanych obszarów funkcjonalnych. Syntetyczny miernik dla wyróżnionego obiektu określa wzór'?

$$
W_{\text {nazwa obiektu }}^{\text {rok }}=\sum_{i=1}^{n} w_{i} x_{i j}^{\prime}
$$

Ze względu na charakter badania zastosowano zmienną agregatową, w której system wag został oparty na systemie wag stałych. Waga składowej tworzącej zmienną syntetyczną nie jest uzależniona od poziomu zmienności danej cechy. Wobec tego miernik uzyskany z takiej agregacji, nie jest wrażliwszy na zmiany wewnątrz danej cechy.

\section{WYNIKI BADANIA}

W pierwszej części analizy wyznaczono wartości wskaźników syntetycznych dla poszczególnych determinant (grup wskaźników) z tabl. 1 w odniesieniu do badanych OBSZARÓW FUNKCJONALYCH w latach 2010 i 2016. Pierwszy czasookres - rok 2010 - gdy nie istniały obszary funkcjonalne i drugi - rok 2016 dla najnowszych dostępnych danych. Otrzymano następujące rezultaty zawarte w tabl. 2-6.

\footnotetext{
${ }^{6}$ T. Grabiński, Wielowymiarowa analiza porównawcza $w$ badaniach dynamiki zjawisk ekonomicznych, Zeszyty Naukowe Akademii Ekonomicznej w Krakowie, Seria specjalna: Monografie, nr 61, Kraków 1984, s. 11-15.

7 K. Kukuła, Metody ilościowe w badaniach ekonomicznych, Vol. XIII/1, Szkoła Główna Gospodarstwa Wiejskiego, Wydział Zastosowań Informatyki i Matematyki, Katedra Ekonometrii i Statystyki, Warszawa 2012, s. 5.

8 Ibidem, s. 9.

9 W. Ostasiewicz, Statystyczne metody analizy danych, Wrocław 1999, s. 113.
} 
Tabela 2. Wskaźnik syntetyczny dla determinanty RYNEK PRACY i EDUKACJA

\begin{tabular}{|l|c|c|c|c|c|}
\hline \multirow{2}{*}{ Obszar funkcjonalny } & \multirow{2}{*}{2010} & \multirow{2}{*}{2016} & Zmiana wartości & \multicolumn{2}{c|}{ Lokata } \\
\cline { 5 - 7 } & & & $2016-2010$ & 2010 & 2016 \\
\hline Aglomeracja Opolska & 0,674 & 0,978 & + & 2 & 1 \\
\hline Kluczbork - Namysłów - Olesno & 0,526 & 0,661 & + & 3 & 2 \\
\hline Subregion Brzeski & 0,138 & 0,201 & + & 4 & 4 \\
\hline Subregion Kędzierzyńsko-Strzelecki & 0,730 & 0,617 & - & 1 & 3 \\
\hline Partnerstwo Nyskie 2020 & 0,040 & 0,172 & + & 5 & 5 \\
\hline
\end{tabular}

Pod względem RYNKU PRACY i EDUKACJI najlepsze wyniki w roku 2016 uzyskała Aglomeracja Opolska. Na pierwszą wpłynęło lokatę wpłynęły m.in. najlepsze wskaźniki rynku pracy: największa liczba pracujących na 100 osób w wieku produkcyjnym, przy jednocześnie najmniejszej liczbie bezrobotnych zarejestrowanych na 100 osób w wieku produkcyjnym. Dla obszaru funkcjonalnego Subregion Kędzierzyńsko-Strzeleckiego nastąpił spadek pozycji w stosunku do roku 2010 oraz nastąpiło pogorszenie wartości wskaźników ją tworzących.

Tabela 3. Wskaźnik syntetyczny dla determinanty OCHRONA ZDROWIA i POMOC SPOŁECZNA

\begin{tabular}{|c|c|c|c|c|c|}
\hline \multirow{2}{*}{ Obszar funkcjonalny } & \multirow{2}{*}{2010} & \multirow{2}{*}{2016} & \multirow{2}{*}{$\begin{array}{c}\text { Zmiana wartości } \\
\text { 2016-2010 }\end{array}$} & \multicolumn{2}{|c|}{ Lokata } \\
\hline & & & & 2010 & 2016 \\
\hline Aglomeracja Opolska & 0,602 & 0,776 & + & 1 & 1 \\
\hline Kluczbork - Namysłów - Olesno & 0,450 & 0,395 & - & 5 & 3 \\
\hline Subregion Brzeski & 0,491 & 0,160 & - & 4 & 5 \\
\hline Subregion Kędzierzyńsko-Strzelecki & 0,554 & 0,516 & - & 3 & 2 \\
\hline Partnerstwo Nyskie 2020 & 0,555 & 0,331 & - & 2 & 4 \\
\hline
\end{tabular}

W odniesieniu do OCHRONY ZDROWIA i POMOCY SPOŁECZNEJ dominowała Aglomeracja Opolska. O zajęciu przez Aglomerację pierwszej lokaty zadecydowały m.in.: największa liczba przychodni w przeliczeniu na 10 tys. mieszkańców oraz liczba dzieci w żłobkach przypadająca na 100 miejsc w tych placówkach. Zmianę lokaty In plus odnotowano dla obszarów funkcjonalnych: Kluczbork - Namysłów - Olesno oraz Subregionu Kędzierzyńsko-Strzeleckiego. Tylko w przypadku Aglomeracji Opolskiej nastąpiła poprawa wartości wskaźników ją tworzących.

Tabela 4. Wskaźnik syntetyczny dla determinanty KULTURA, TURYSTYKA I SPORT

\begin{tabular}{|l|c|c|c|c|c|}
\hline \multirow{2}{*}{ Obszar funkcjonalny } & \multirow{2}{*}{2010} & \multirow{2}{*}{2016} & Zmiana wartości & \multicolumn{2}{c|}{ Lokata } \\
\cline { 5 - 7 } & & & $2016-2010$ & 2010 & 2016 \\
\hline Aglomeracja Opolska & 0,613 & 0,565 & - & 1 & 1 \\
\hline Kluczbork - Namysłów - Olesno & 0,423 & 0,272 & - & 3 & 5 \\
\hline Subregion Brzeski & 0,418 & 0,294 & - & 4 & 3 \\
\hline Subregion Kędzierzyńsko-Strzelecki & 0,321 & 0,280 & - & 5 & 4 \\
\hline Partnerstwo Nyskie 2020 & 0,570 & 0,561 & - & 2 & 2 \\
\hline
\end{tabular}


Pod względem KULTURA, TURYSTYKA I SPORT najlepsze wyniki uzyskała Aglomeracja Opolska, które miała m.in. największą liczbę czytelników przeliczeniu na 1 tys. ludności, widzów w kinach przeliczeniu na 1 tys. ludności, jak i ćwiczących w przeliczeniu na 10 tys. ludności. Zmianę lokaty In plus odnotowano dla Subregionu Brzeskiego i Subregionu Kędzierzyńsko-Strzeleckiego. Dla żadnego obszaru funkcjonalnego nie zanotowano poprawy wartości wskaźników ją tworzących.

Tabela 5. Wskaźnik syntetyczny dla determinanty INFRASTRUKTURA KOMUNALNA I MIESZKANIA

\begin{tabular}{|c|c|c|c|c|c|}
\hline \multirow{2}{*}{ Obszar funkcjonalny } & \multirow{2}{*}{2010} & \multirow{2}{*}{2016} & \multirow{2}{*}{$\begin{array}{c}\text { Zmiana wartości } \\
\text { 2016-2010 }\end{array}$} & \multicolumn{2}{|c|}{ Lokata } \\
\hline & & & & 2010 & 2016 \\
\hline Aglomeracja Opolska & 0,915 & 0,977 & + & 1 & 1 \\
\hline Kluczbork - Namysłów - Olesno & 0,118 & 0,203 & + & 5 & 5 \\
\hline Subregion Brzeski & 0,649 & 0,636 & - & 2 & 2 \\
\hline Subregion Kędzierzyńsko-Strzelecki & 0,583 & 0,560 & + & 3 & 3 \\
\hline Partnerstwo Nyskie 2020 & 0,195 & 0,204 & + & 4 & 4 \\
\hline
\end{tabular}

Odnośnie do INFRASTRUKTURY KOMUNALNEJ i MIESZKAŃ dominowała Aglomeracja Opolska, na terenie której oddano najwięcej mieszkań do użytkowania na 10 tys. ludności oraz notowano największą gęstość sieci wodociągowej i kanalizacyjnej. Wszystkie obszary funkcjonalne utrzymały swoje lokaty z roku $2010 \mathrm{w}$ roku 2016. Pogorszenie wartości wskaźników zanotowano dla Subregionu Brzeskiego.

Tabela 6. Wskaźnik syntetyczny dla determinanty STAN I OCHRONA ŚRODOWISKA

\begin{tabular}{|l|c|c|c|c|c|}
\hline \multicolumn{1}{c|}{ Obszar funkcjonalny } & \multirow{2}{*}{2010} & \multirow{2}{*}{2016} & $\begin{array}{c}\text { Zmiana wartości } \\
2016-2010\end{array}$ & \multicolumn{2}{c|}{ Lokata } \\
\cline { 5 - 7 } & & & 2010 & 2016 \\
\hline Aglomeracja Opolska & 0,679 & 0,723 & + & 1 & 2 \\
\hline Kluczbork - Namysłów - Olesno & 0,592 & 0,594 & + & 3 & 3 \\
\hline Subregion Brzeski & 0,487 & 0,486 & - & 4 & 4 \\
\hline Subregion Kędzierzyńsko-Strzelecki & 0,654 & 0,813 & + & 2 & 1 \\
\hline Partnerstwo Nyskie 2020 & 0,408 & 0,187 & - & 5 & 5 \\
\hline
\end{tabular}

Odnośnie do STANU I OCHRONY ŚRODOWISKA najwyższą lokatę w 2016 r. uzyskał Subregion Kędzierzyńsko - Strzelecki, na terenie którego znacząco zmniejszono ilość zmieszanych odpadów komunalnych w przeliczeniu na 1 mieszkańca w kg oraz zwiększono liczbę osób korzystających z oczyszczalni ścieków komunalnych. Dla obszaru funkcjonalnego Aglomeracji Opolskiej zanotowano spadek pozycji w stosunku do roku 2010. Poprawy wartości wskaźników tworzących ta determinantę zanotowano dla tego obszaru, Kluczbork -Namysłów - Olesno i Subregionu Kędzierzyńsko-Strzeleckiego. 
Tabela 7. Wskaźnik syntetyczny ATRAKCYJNOŚĆ OSIEDLEŃCZA

\begin{tabular}{|l|c|c|c|c|c|}
\hline \multirow{2}{*}{ Obszar funkcjonalny } & \multirow{2}{*}{2010} & \multirow{2}{*}{2016} & Zmiana wartości & \multicolumn{2}{c|}{ Lokata } \\
\cline { 5 - 7 } & & & $2016-2010$ & 2010 & 2016 \\
\hline Aglomeracja Opolska & 0,677 & 0,749 & + & 1 & 1 \\
\hline Kluczbork - Namysłów - Olesno & 0,412 & 0,375 & - & 5 & 3 \\
\hline Subregion Brzeski & 0,445 & 0,336 & - & 3 & 5 \\
\hline Subregion Kędzierzyńsko-Strzelecki & 0,506 & 0,484 & - & 2 & 2 \\
\hline Partnerstwo Nyskie 2020 & 0,418 & 0,358 & - & 4 & 4 \\
\hline
\end{tabular}

Najwyższy wskaźnik ATRAKCYJNOŚCI OSIEDLEŃCZEJ uzyskała Aglomeracja Opolska, która dominowała pod względem RYNKU PRACY i EDUKACJI, OCHRONY ZDROWIA i POMOCY SPOŁECZNEJ, KULTURY, TURYSTYKI I SPORTU, a także INFRASTRUKTURY KOMUNALNEJ I MIESZKAŃ.

Drugi co do wielkości wskaźnik ATRAKCYJNOŚCI OSIEDLEŃCZEJ osiągnął Subregion Kędzierzyńsko-Strzelecki, który najlepsze wyniki uzyskał pod względem STANU I OCHRONY ŚRODOWISKA. Wysoką pozycję Subregion zajął także w obszarze OCHRONY ZDROWIA i POMOCY SPOEECZNEJ.

Najniższy wskaźnik ATRAKCYJNOŚCI OSIEDLEŃCZEJ w 2016 r. odnotowano w Subregionie Brzeskim, przy czym warty podkreślenia jest fakt, że obszar ten miał wysoką pozycję w zakresie INFRASTRUKTURY KOMUNALNEJ i MIESZKAŃ.

Zauważyć również należy, że tylko dla Aglomeracji Opolskiej nastąpił i wzrost wartości wskaźnika syntetycznego określającego ATRAKCYJNOŚĆ OSIEDLEŃCZĄ na badanych obszarach funkcjonalnych w województwie opolskim.

\section{UWAGI}

Wszystkie kategorie badawcze, które wyróżniono po analizie treści dokumentów strategicznych badanych obszarów funkcjonalnych są kluczowe dla rozwoju tych obszarów. Ze względu na złożony charakter podlegać powinny analizie przy pomocy metod wielowymiarowej analizy porównawczej.

Grupy wskaźników je określających są zdeterminowane dostępnością i subiektywną oceną ich charakteru. W niniejszym opracowaniu zbadano atrakcyjność osiedleńczą obszaru funkcjonalnego, gdyż była to jedyna kategoria dla której po analizie zastanych danych statystycznych wskaźniki ją określające cechowała dostępność. Nasuwają się zatem następujące wnioski.

Do wyzwań związanych z analiza danych dla tych obszarów zaliczyć należy informację, iż obszar funkcjonalny jest nowym, a tym samym mało zbadanym obiektem do badań ilościowych, ale również uzupełniająco jakościowych. Dane tworzone na podstawie kumulacji jednostek administracyjnych na poziomie NTS 5 (gmin) dają szerokie możliwości w kwestii badań terenowych dla kategorii naukowych mających potencjalnie istotny wpływ na rozwój tych obszarów.

Do ograniczeń związanych $\mathrm{z}$ analiza danych dla tych obszarów zaliczyć należy: małą dostępność danych na poziomie pomiaru NTS 5 (gmin), a właściwie ich deficyt. Kolejnym 
ograniczeniem jest niewielką liczebność obiektów badań (w przypadku województwa opolskiego tylko pięć obiektów).

Na zakończenie prowadzonych rozważań należy podkreślić, iż problematyka analizy danych dla nieadministracyjnych podziałów regionu jest ważna z punktu widzenia badania istotnych czynników rozwoju regionalnego i lokalnego.

\section{LITERATURA}

1. Grabiński T., Wielowymiarowa analiza porównawcza w badaniach dynamiki zjawisk ekonomicznych, Zeszyty Naukowe Akademii Ekonomicznej w Krakowie, Seria specjalna: Monografie, nr 61, Kraków 1984.

2. Kukuła K., Metody ilościowe w badaniach ekonomicznych, Vol. XIII/1, Szkoła Główna Gospodarstwa Wiejskiego, Wydział Zastosowań Informatyki i Matematyki, Katedra Ekonometrii i Statystyki, Warszawa 2012.

3. Ostasiewicz W., Statystyczne metody analizy danych, Wydawnictwo Akademii Ekonomicznej, Wrocław 1999.

4. Strategia Rozwoju Województwa Opolskiego do roku 2020, Urząd Marszałkowski Województwa Opolskiego, Departament Polityki Regionalnej i Przestrzennej, Opole 2012.

\section{PRAWODAWSTWO}

1. Ustawa z dnia 27 marca 2003 r. o planowaniu i zagospodarowaniu przestrzennym (Dz.U. z 2017, poz. 1073, 1566).

\section{NETOGRAFIA}

1. Strategia Rozwoju Aglomeracji Opolskiej na lata 2014-2020: https://aglomeracja-opolska.pl/rpo-wo-2014-2020/zapoznaj-sie-z-prawem-i-dokumentami/ dokumenty- strategiczne - ao.

2. Strategia Rozwoju Obszaru Funkcjonalnego Partnerstwo Nyskie 2020: http://partnerstwo-nyskie2020.pl/index.php/strategie.

3. Strategia Rozwoju Współpracy Subregionu Brzeskiego na lata 2014-2020 z perspektywą do roku 2025: http://www.subregionbrzeski.pl/dokumenty.html.

4. Strategia Rozwoju Subregionu Kędzierzyńsko - Kozielskiego do roku 2020: http://www. subregionkk.pl/index.php/dokumenty-strategiczne.

5. Strategia Rozwoju Obszaru Funkcjonalnego Kluczbork - Namysłów - Olesno: http:// www.powiatkluczborski.pl/aktualnosci/strat_of/Strategia_Rozwoju_OF_KNO_14_01_15. pdf.

\section{TESTING OF FUNCTIONAL AREAS IN OPOLSKIE VOIVODESHIP - LIMITATIONS AND CHALLENGES OF DATA ANALYSIS FOR NON-ADMINISTRATIVE REGION DISTRIBUTION}

The aim of the article is to show functional areas as quantitative research objects. Their creation was a response to the needs of local communities to solve problems together. A functional area is an area of a special phenomenon in the spatial economy or the presence of spatial conflicts that constitutes a compact spatial arrangement consisting of functionally related 
areas characterized by common conditions and anticipated uniform development goals. An analysis of strategic documents indicated research categories important from the point of view of development of these areas. The specified determinants are: labor market and education, health care and social assistance, culture, tourism and sport, municipal infrastructure and housing, condition and environmental protection. With the aid of a synthetic variable, the indicator of settlement attractiveness was constructed for these areas. The highest rate of settlement attractiveness was obtained by the Opole Agglomeration, which dominated in terms of the labor market and education, health care and social assistance, culture, tourism and transport, as well as municipal infrastructure and housing. The article is an attempt to indicate the limitations and challenges of data analysis for non-administrative divisions of the region. The research was carried out in two periods: in 2010 (when there were no areas yet) and in 2016 for the latest available data. The analyzes were performed using the EXCEL calculation software using one of the methods of multidimensional comparative analysis. The issue of data analysis for non-administrative divisions of the region is important from the point of view of the study of important factors of regional and local development.

Keywords: development strategy, settlement attractiveness, synthetic variable, area functional, data accumulation at NTS 5 level.

DOI: $10.7862 /$ rz.2018.hss.34

Przestano do redakcji: kwiecień $2018 r$.

Przyjęto do druku: czerwiec 2018 r. 